\title{
The sentinel node in gynaecological malignancies
}

\author{
J Balega and P O Van Trappen \\ The Gynaecological Cancer Centre, St Bartholomew's Hospital, Queen Mary University, London, West Smithfield, \\ London, ECIA 7BE, UK \\ Corresponding address: P O Van Trappen, The Gynaecological Cancer Centre, St Bartholomew's Hospital, \\ West Smithfield, London, ECIA 7BE, UK \\ E-mail: p.o.vantrappen@qmul.ac.uk
}

Date accepted for publication 21 November 2005

\begin{abstract}
As lymph node metastasis is one of the earliest features of tumour cell spread in most human cancers, assessment of the regional lymph nodes is required for tumour staging, determining prognosis and planning adjuvant therapeutic strategies. However, complete lymph node dissections are frequently associated with significant complications. Conjugating the diagnostic advantages with decreased morbidity, the sentinel node concept represents one of the most recent advances in surgical oncology. In this review we briefly highlight the historical background of the development of the sentinel node concept, the anatomical evidence for applying the sentinel node concept in pelvic gynaecological cancers and the technical aspects of sentinel node detection. We discuss recent studies in vulval, cervical and endometrial cancer.
\end{abstract}

Keywords: Sentinel node; lymphatic mapping; cervical cancer; vulval cancer; endometrial cancer.

\section{Introduction}

During the past two decades the operative management of cancer has changed to a large extent. In breast cancer, the Rotter-Halstedt radical surgical procedure has been replaced more and more by a breast-conserving treatment combined with adjuvant local (radiotherapy) and systemic (hormonal and/or chemotherapy) treatment. The less ablative surgical management has resulted in a significant decrease in morbidity whilst retaining a similar survival rate.

As lymph node metastasis is one of the earliest features of tumour cell spread in most human cancers, assessment of the regional lymph nodes is required for tumour staging, determining prognosis and planning adjuvant therapeutic strategies. In most solid tumours, dissection of all regional lymph nodes is part of the surgical procedure; however, in breast cancer and cutaneous malignant melanoma this has been replaced by dissection of the sentinel lymph node(s) only. The sentinel node
(SN) is defined as the very first lymph node or group of nodes that drain the anatomical region or primary tumour $^{[1,2]}$. The status of the SN should represent the whole lymphatic area, i.e. if the $\mathrm{SN}$ is negative the non-sentinel lymph nodes should also be negative. The application of the SN dissection (SND) in breast cancer has resulted in a further decrease in morbidity, especially the formation of lymphoedema, by avoiding a complete axillary lymph node dissection ${ }^{[3-5]}$.

The SN concept is based on the detection of $\mathrm{SN}(\mathrm{s})$ using both dye-based and gammaprobe-guided methods (radioimmunoscintigraphy), and removal of the identified $\mathrm{SN}(\mathrm{s})$ with subsequent histological analysis. The detection rate of small clusters of (micro)metastases in $\mathrm{SN}(\mathrm{s})$ can be increased when the nodes are subjected to serial sectioning and the use of immunohistochemistry, i.e. antibodies against epithelial markers ${ }^{[6]}$.

In this review we briefly highlight the historical background of the development of the SN concept, the anatomical evidence for applying the $\mathrm{SN}$ concept in

This paper is available online at http://www.cancerimaging.org. In the event of a change in the URL address, please use the DOI provided to locate the paper. 
pelvic gynaecological cancers and the SN technology. We discuss recent reports on the application of the SN method in vulval, cervical and endometrial cancer.

\section{Historical background}

In 1960, Gould et al. established the term 'sentinel node' (SN) when they published their report on parotid gland cancer $^{[1]}$. In 1977, Cabanas proposed the SN concept in the management of patients with penile cancer, and he reported that the lymphatic drainage of the penis merges into a group of lymph nodes called 'sentinel lymph nodes' (SLNs) ${ }^{[2]}$. He used lymphography to visualise the dorsal lymphatics of the penis draining to the lymph nodes close to the superficial epigastric vein. In 1992, Morton et al. introduced the SN method in the management of cutaneous malignant melanoma. Blue dye was injected around the lesion just before the operation and the nodes staining blue were removed via a small incision ${ }^{[7]}$. In $82 \%$ of cases, the $\mathrm{SN}$ was successfully identified; the false negative rate was less than $1 \%$. The application of technetium-99m-labelled nannocolloid as a more sophisticated detection method for $\mathrm{SN}(\mathrm{s})$ was introduced into the management of malignant melanoma in 1993 by Alex and Kraig. They used both preoperative lymphoscintigraphy as well as an intraoperative handheld gamma probe, which increased the detection rate ${ }^{[8]}$. In 1993 , Krag et al. reported a pilot study on the use of SN identification, using technetium-99m-labelled colloid, in the management of breast cancer; they achieved a detection rate of $81 \%{ }^{[9]}$. In 1994, Giuliano et al. reported in a large series of 174 consecutive breast cancer patients the use of blue dye as a method for $\mathrm{SN}$ detection; the detection rate was $65.5 \%$ and accurately predicted the axillary nodal status in $95.6 \%$ of cases ${ }^{[10]}$. In the same year, Levenback et al. published the first feasibility study on SND in vulval cancer. They administered intracutaneous isosulfan blue and identified SN(s) in 77\% of cases, with no false negatives ${ }^{[11]}$. At present, ongoing multicentre prospective observational studies (GOG173 and the European trial led by A. Van der Zee) are addressing the clinical implementation of SN detection in vulval cancer management. Since 1999, several series have been reported on the feasibility of SN detection in cervical and endometrial cancer as well as its validity ${ }^{[12-17]}$. The modality of injecting the dye or radioactive tracer for SN detection has still to be established in endometrial cancer. In cervical cancer, there is some concern whether the SN accurately predicts the pelvic lymph node status, however, most series demonstrate a low false negative rate $^{[14,18]}$ (see Table 2). For early-stage breast cancer and malignant melanoma, the SN concept has become the standard care without altering the survival rate but with a significant decrease in the morbidity of lymph node dissection $^{[19-21]}$.

\section{Anatomical background: the lymphatic drainage of the female genital tract}

The lymphatic vessels from the vulval region terminate primarily in the inguinal nodes. The fine lymphatic vessels from the labium minora, the fourchette, and the vaginal mucosa up to the level of the hymenal ring extend towards the anterior aspect of the labium minora where they emerge into few major collecting vessels ${ }^{[22]}$. The lymphatic vessels from the prepucium and the labium majora also join these main vessels, which terminate in the primary inguinofemoral lymph nodes. These firstline nodes are located medial to the saphenus vein and above the cribriform fascia and are called superficial nodes (about 8-10 in number); the deep nodes are situated in the openings in the cribriform fascia ${ }^{[23-25]}$. The uppermost deep lymph node located under the inguinal (Poupart) ligament is called the Cloquet or Rosenmüller node and leads to the lymphatics around the external iliac vessels. The lymphatic vessels from the vulva do not cross the midline except those coming from the median structures, i.e. the clitoris and perineum. Although lymphatics from the clitoris can lead directly to the pelvic nodes, practically there is no sole pelvic lymph node involvement without inguinal node metastasis ${ }^{[26]}$. In the case of positive inguinal nodes, however, pelvic node metastasis is present in $25 \%$ of cases.

The uterine cervix has copious lymphatic drainage consisting of primary and secondary groups of lymph nodes ${ }^{[27]}$. The group of primary nodes consists of parametrial, paracervical, obturator, hypogastric, external iliac, and presacral lymph nodes. The common iliac, paraaortic and inguinal lymph nodes constitute the secondary group. Obturator nodes are the most likely to be involved by tumour metastasis followed by the external iliac, common iliac, and parametrial lymph nodes in locally advanced cervical cancer ${ }^{[28]}$. Skip metastasis, i.e. paraaortic lymph node involvement without pelvic lymph node metastasis, is rare, accounting for only $1 \%$ of cases ${ }^{[29,30]}$. The SN in cervical cancer is situated in the obturator region in $43 \%$ of cases and the external iliac region in $45 \%-84 \%$ of cases ${ }^{[13,18,29,30]}$.

The lymphatic drainage pattern of the uterine corpus is much more complex, having a bipartite and bilateral drainage system. The lower uterine segment drains to the pelvic lymph nodes via the broad ligaments, and the upper segment of the corpus drains into the paraaortic lymph nodes via the ovarian lymphatics. In a feasibility study by Burke et al., injection of vital blue dye into the corpus revealed a wide variation in the location of pelvic lymph nodes taking up the blue dye ${ }^{[31]}$.

\section{Technique of sentinel node detection}

There are two methods described for SN identification: vital dyes and radioactive tracers. The three dyes most 
Table 1 Sentinel node in vulval cancer

\begin{tabular}{|c|c|c|c|c|c|c|c|c|c|}
\hline $\begin{array}{l}\text { Author } \\
\text { [reference] }\end{array}$ & Year & $\begin{array}{l}\text { Detection } \\
\text { method }\end{array}$ & $\begin{array}{l}\text { No. of } \\
\text { cases }\end{array}$ & $\begin{array}{c}\text { Groins } \\
\text { dissected }(n)\end{array}$ & $\begin{array}{l}\text { Detection } \\
\text { rate }(\%)\end{array}$ & $\begin{array}{l}\text { Positive } \\
\text { SN }(n)\end{array}$ & $\begin{array}{l}\text { False negative } \\
\text { SN }(\mathrm{N})\end{array}$ & $\begin{array}{l}\text { NPV } \\
(\%)\end{array}$ & Ultra-staging \\
\hline Levenback ${ }^{[65]}$ & 1995 & $\mathrm{BD}$ & 21 & 29 & 66 & 5 & 0 & 100 & $\mathrm{~N}$ \\
\hline Decesare $^{[58]}$ & 1997 & ILS & 10 & 20 & 100 & 3 & 0 & 100 & $\mathrm{~N}$ \\
\hline $\operatorname{Echt}^{[12]}$ & 1999 & $\mathrm{BD}$ & 12 & 23 & 75 & 2 & 0 & ND & $\mathrm{N}$ \\
\hline $\operatorname{Rodier}^{[66] \mathrm{a}}$ & 1999 & $\mathrm{ILS}+\mathrm{BD}$ & 8 & ND & 100 & 1 & 0 & ND & $\mathrm{N}$ \\
\hline Ansink ${ }^{[67]}$ & 1999 & $\mathrm{BD}$ & 51 & 93 & 56 & 9 & 2 & 95 & $\mathrm{~N}$ \\
\hline Terada ${ }^{[38] \mathrm{a}}$ & 2000 & $\mathrm{ILS}+\mathrm{BD}$ & 9 & 2 & 100 & 3 & 0 & 100 & $\mathrm{Y}$ \\
\hline De Hullu ${ }^{[68]}$ & 2000 & ILS BD & 59 & 107 & 100 & 24 & 0 & 100 & $\mathrm{Y}$ \\
\hline Sideri ${ }^{[69]}$ & 2000 & ILS & 44 & 77 & 100 & 13 & 0 & 100 & $\mathrm{~N}$ \\
\hline De Cicco ${ }^{[70]}$ & 2000 & ILS & 37 & 55 & 100 & 8 & 0 & 100 & $\mathrm{~N}$ \\
\hline Levenback $^{[71]}$ & 2001 & $\mathrm{BD}$ & 52 & 76 & 88 & 10 & 0 & 100 & Y \\
\hline Boran ${ }^{[53]}$ & 2003 & ILS & 10 & 17 & 100 & 4 & 2 & 83 & Y \\
\hline Molpus ${ }^{[72]}$ & 2001 & $\mathrm{ILS}+\mathrm{BD}$ & 11 & 16 & 91 & 3 & 0 & 100 & Y \\
\hline Tavares $^{[73]}$ & 2001 & $\mathrm{ILS}+\mathrm{BD}$ & 15 & ND & 100 & 3 & 0 & 100 & $\mathrm{~N}$ \\
\hline Sliutz ${ }^{[74]}$ & 2002 & $\mathrm{ILS} \pm \mathrm{BD}$ & 26 & 46 & 100 & 9 & 0 & 100 & Y \\
\hline Moore $^{[75]}$ & 2003 & $\mathrm{ILS}+\mathrm{BD}$ & 21 & 31 & 100 & 7 & 0 & 100 & Y \\
\hline Puig-Tintore ${ }^{[37]}$ & 2003 & $\mathrm{ILS}+\mathrm{BD}$ & 26 & 37 & 96 & 8 & 0 & 100 & Y \\
\hline Merisio $^{[76]}$ & 2005 & ILS & 20 & 30 & 100 & 2 & 1 & 95 & $\mathrm{Y}$ \\
\hline Louis-Sylvestre ${ }^{[77]}$ & 2005 & $\mathrm{ILS} \pm \mathrm{BD}$ & 17 & 34 & 100 & 0 & 5 & 100 & $\mathrm{Y}$ \\
\hline
\end{tabular}

aTherapeutic, no complete LND after SND; BD, blue dye method; ILS, intraoperative lymphoscintigraphy; NPV, negative predictive value; SN, sentinel node; ND, no data.

commonly used are isosulfan blue, patent blue violet, and methylene blue. In most studies the dye has been injected peri-tumourly, where most lymphatic vessels are, up to 20 min before surgery. Blue-stained lymphatic vessels and nodes can already be visualised a few minutes after injection. Intratumoural and intravascular administration have to be avoided as it can produce high background signal intensity ('shine through') and can decrease the rate of identification. The blue dye method is an inexpensive, rapid and visible technique, easy to handle and represents no radiobiological hazards. Hypersensitive reaction to the blue dye is extremely uncommon. The significant drawbacks of the blue dye method are the need for a larger incision for better visualisation and a lower detection rate $(60 \%-90 \%)$ (see Tables 1 and 2). Radioactive tracers contain technetium- $99 \mathrm{~m}$ radioisotope bound to nannoparticles like colloidal sulphur or human albumin. To detect the node(s) with the highest uptake of technetium-99m, preoperative scintigraphy and an intraoperative handheld gamma probe are used. The radioactive tracer has to be injected also peri-tumourly, 1 day prior to surgery and a locoregional scintigraphy is performed the same day in order to roughly localise the site of the $\mathrm{SN}(\mathrm{s})$. An intraoperative handheld gamma probe is used to accurately localise the $\mathrm{SN}(\mathrm{s})$, using a 10 -fold increase in radiation compared to basal count as a limit. Compared to blue dye, lymphoscintigraphy is a quantitative and highly sensitive method, but is costly and needs nuclear medicine studies and more preparation.
A combination of both techniques achieves a higher detection rate when compared to blue dye alone ${ }^{[32]}$.

\section{Histopathological evaluation}

One of the key issues of the $\mathrm{SN}$ concept is the histological assessment of the lymph node specimen(s). The first step is intraoperative frozen section analysis, however, this has a low sensitivity for detecting metastases; the false negative rate of identifying micrometastases can be as high as $70 \%{ }^{[33-36]}$. Standard sectioning with haematoxylin and eosin staining is not as sensitive as serial sectioning combined with immunohistochemistry (IHC) to detect micrometastases ${ }^{[6]}$. In vulval cancer, approximately $40 \%$ of SN (micro)metastases are only detected when using serial sectioning ${ }^{[37-39]}$. Serial sectioning, with reported variable intervals between 50 and $400 \mu \mathrm{m}$, and the use of a pancytokeratin antibody (AE1/AE3) enhances the detection rate of nodal micrometastases ${ }^{[14]}$. In contrast, Hakam et al. found no additional benefit of serial sectioning ${ }^{[40]}$. Lymph node micrometastasis in breast cancer has now been included in the TNM classification, with micrometastases defined as clusters between $200 \mu \mathrm{m}$ and $2 \mathrm{~mm}^{[41]}$. In endometrial cancer, detection of cytokeratinpositive micrometastases in presumed histologically node-negative patients may predict recurrent disease ${ }^{[42]}$. Molecular techniques such as real time polymerase chain reaction (RT-PCR) targeting detection of mutations or 
Table 2 Sentinel node in cervical cancer

\begin{tabular}{|c|c|c|c|c|c|c|c|c|c|}
\hline $\begin{array}{l}\text { Author } \\
\text { [reference] }\end{array}$ & Year & $\begin{array}{l}\text { Detection } \\
\text { method }\end{array}$ & Surgery & $\begin{array}{l}\text { No. of } \\
\text { cases }\end{array}$ & $\begin{array}{c}\text { Detection } \\
\text { rate }(\%)\end{array}$ & $\begin{array}{l}\text { Positive } \\
\text { SN }\end{array}$ & $\begin{array}{c}\text { False negative } \\
\text { SN }\end{array}$ & $\begin{array}{l}\text { NPV } \\
(\%)\end{array}$ & Ultra-staging \\
\hline $\operatorname{Echt}^{[12]}$ & 1999 & $\mathrm{BD}$ & LAP & 13 & 23 & 2 & 1 & ND & $\mathrm{N}$ \\
\hline Dargent ${ }^{[13]}$ & 2000 & $\mathrm{BD}$ & LSC & 35 & 86 & 8 & 0 & 100 & $\mathrm{~N}$ \\
\hline Verheijen ${ }^{[78]}$ & 2000 & $\mathrm{ILS}+\mathrm{BD}$ & LAP & 10 & 80 & 1 & 0 & 100 & $\mathrm{Y}$ \\
\hline O'Boyle $^{[79]}$ & 2000 & $\mathrm{BD}$ & LAP & 20 & 60 & 3 & 1 & 89 & $\mathrm{~N}$ \\
\hline Kamprath $^{[80]}$ & 2000 & ILS & LSC & 18 & 89 & 1 & 0 & 100 & ND \\
\hline Malur $^{[81]}$ & 2001 & ILS or BD & LAP/LSC & 50 & 80 & 6 & 01 & 97 & $\mathrm{~N}$ \\
\hline Lantzsch $^{[82]}$ & 2001 & ILS & LAP & 14 & 93 & 1 & 0 & 100 & $\mathrm{Y}$ \\
\hline Levenback $^{[30]}$ & 2002 & $\mathrm{ILS}+\mathrm{BD}$ & LAP & 39 & 100 & 8 & 1 & 97 & $\mathrm{Y}$ \\
\hline Rhim $^{[83]}$ & 2002 & $\mathrm{ILS}+\mathrm{BD}$ & LAP & 26 & 100 & 5 & 1 & 95 & $\mathrm{~N}$ \\
\hline Plante $^{[32]}$ & 2003 & $\begin{array}{l}\mathrm{BD} \\
\mathrm{BD}+\mathrm{ILS}\end{array}$ & LSC & $\begin{array}{l}41 \\
29\end{array}$ & $\begin{array}{l}79 \\
93\end{array}$ & 12 & 0 & 100 & $\mathrm{Y}$ \\
\hline Dargent $^{[14]}$ & 2003 & $\mathrm{BD}$ & LSC & 70 & 90 & 19 & 0 & 100 & $\mathrm{Y} / \mathrm{N}$ \\
\hline Lambaudie $^{[84]}$ & 2003 & $\mathrm{ILS}+\mathrm{BD}$ & LSC & 12 & 92 & 2 & 1 & 89 & $\mathrm{Y}$ \\
\hline Barranger $^{[16]}$ & 2003 & $\mathrm{ILS}+\mathrm{BD}$ & LSC & 13 & 92 & 2 & 0 & 100 & $\mathrm{Y}$ \\
\hline Chung [85] & 2003 & $\mathrm{ILS}+\mathrm{BD}$ & LAP & 26 & 100 & 1 & 0 & 100 & ND \\
\hline Buist $^{[86]}$ & 2003 & $\mathrm{ILS}+\mathrm{BD}$ & LSC & 25 & 100 & 9 & 1 & 94 & $\mathrm{Y}$ \\
\hline Hubalewska ${ }^{[87]}$ & 2003 & $\mathrm{ILS}+\mathrm{BD}$ & LAP & 37 & 100 & 5 & ND & ND & ND \\
\hline Van Dam ${ }^{[88]}$ & 2003 & ILS & LSC & 25 & 84 & 5 & 0 & 100 & ND \\
\hline Martinez-Palones [89] & 2004 & $\mathrm{ILS}+\mathrm{BD}$ & LSCLAP & 25 & 92 & 4 & 0 & 100 & $\mathrm{Y}$ \\
\hline $\mathrm{Li}^{[90]}$ & 2004 & ILS & LAP & 28 & 96 & 6 & 0 & 100 & ND \\
\hline Marchiole ${ }^{[91]}$ & 2004 & $\mathrm{BD}$ & LSC & 29 & 100 & 2 & 3 & 87.5 & $\mathrm{Y}$ \\
\hline Lelievre $^{[17]}$ & 2004 & $\mathrm{ILS}+\mathrm{BD}$ & LSC & 8 & 71 & 0 & 0 & 100 & $\mathrm{Y}$ \\
\hline Barranger ${ }^{[92]}$ & 2004 & $\mathrm{ILS}+\mathrm{BD}$ & LSC & 18 & 100 & 5 & 0 & 100 & $\mathrm{Y}$ \\
\hline Niikura ${ }^{[93]}$ & 2004 & $\mathrm{ILS}+\mathrm{BD}$ & LAP & 20 & 90 & 2 & 0 & 100 & $\mathrm{Y}$ \\
\hline Pijpers ${ }^{[94]}$ & 2004 & $\mathrm{ILS}+\mathrm{BD}$ & LSC & 34 & 97 & 17 & 1 & 92 & ND \\
\hline Holub ${ }^{[64]}$ & 2004 & $\mathrm{BD}$ & LSC & 7 & 100 & 1 & 0 & 100 & ND \\
\hline Di Stefano ${ }^{[95]}$ & 2005 & $\mathrm{BD}$ & LAP & 50 & 90 & 9 & 1 & 97 & $\mathrm{Y}$ \\
\hline Silva ${ }^{[96]}$ & 2005 & ILS & LAP & 56 & 93 & 10 & 3 & 92 & $\mathrm{Y}$ \\
\hline Angioli $[97]$ & 2005 & ILS & LSC & 37 & 70 & 9 & 0 & 100 & $\mathrm{Y}$ \\
\hline Gil-Moreno ${ }^{998]}$ & 2005 & $\mathrm{ILS}+\mathrm{BD}$ & LSC & 12 & 100 & 0 & 0 & 100 & $\mathrm{Y}$ \\
\hline $\operatorname{Rob}^{[18]}$ & 2005 & $\begin{array}{l}\mathrm{BD} \\
\mathrm{ILS}+\mathrm{BD}\end{array}$ & LSC/LAP & $\begin{array}{r}100 \\
83\end{array}$ & $\begin{array}{l}80 \\
96.4\end{array}$ & $\begin{array}{l}20 \\
15\end{array}$ & $\begin{array}{l}1 \\
0\end{array}$ & $\begin{array}{r}99 \\
100\end{array}$ & $\mathrm{Y}$ \\
\hline $\operatorname{Lin}^{[99]}$ & 2005 & ILS & LAP & 30 & 100 & 7 & 0 & 100 & $\mathrm{Y}$ \\
\hline
\end{tabular}

$\mathrm{BD}$, blue dye method; ILS, intraoperative lymphoscintigraphy; LSC, laparoscopy; LAP, laparotomy; NPV, negative predictive value; SN, sentinel node; ND, no data.

specific gene expressions can even further increase the detection rate of micrometastases. However, the clinical significance of PCR-detected micrometastases remains controversial and requires further prospective validation in a large series ${ }^{[43,44]}$.

\section{Sentinel node in gynaecological cancers}

\section{Vulval cancer}

Vulval cancer accounts for only $4 \%$ of all gynaecological cancers; the mean age of patients is approximately 75 years. In the UK nearly 1000 new patients are diagnosed and more than 350 die every year (Cancer Research UK). Vulval cancer patients represent a special group in gynaecological oncology; impaired tissue healing capacity due to age and common medical problems (e.g. diabetes, hypoproteinaemia, chronic hypertension, obesity) results in a significant postoperative complication rate. Although, the $85 \%$ rate of wound breakdown and the $30 \%-70 \%$ rate of chronic leg oedema following en block radical vulvectomy and bilateral groin node dissection have dropped significantly with the introduction of less extensive surgical techniques, e.g. triple incision technique, radical or wide local excision, the early and late postoperative complication rate following complete groin node dissections are still rankling ${ }^{[45]}$.

As the most significant independent risk factor indicating poor survival is the presence of multiple lymph node metastases, knowledge of the lymph node status is crucial in the selection of a high risk group requiring adjuvant treatment, i.e. radiation or chemoradiation. Inguinal lymph node metastasis in patients with presumed early-stage vulval cancer can be up to $27 \%$, suggesting that the majority of patients undergo a potentially morbid procedure without any benefit ${ }^{[46]}$. Although some encouraging early reports on ultrasound guided fine needle aspiration of lymph nodes and on a special MRI technique using ultra-small-iron-particle 
(Sinerem, Comibdex) have been published, to date there is no reliable method to identify microscopic tumour involvement of the regional lymph nodes ${ }^{[47,48]}$.

In 1979, DiSaia considered the superficial inguinal lymph nodes as the first draining sites in the lymphatic chain of the vulva ${ }^{[49]}$. He proposed limited inguinal node dissection in the case of negative superficial nodes. However, in a Gynecologic Oncology Group (GOG) study published by Stehman et al., an unexpectedly high incidence of groin node recurrence following superficial groin node dissection was found ${ }^{[50,51]}$. Recurrence in the groin is known to be most likely fatal in outcome, which emphasises that any attempt to adopt a more conservative approach to groin node dissection must be carefully and critically evaluated.

In 1994, Levenback reported the use of blue dye in the detection of $\mathrm{SN}(\mathrm{s})$ in vulval squamous cell carcinoma and found that the presence of metastasis in the $\mathrm{SN}$ was representative of the whole inguinal region ${ }^{[11]}$ (see Table 1). In 1997, Decesare et al. published the first series on SN detection in vulval cancer using Tc-99m and further studies proved the SN concept to be a feasible and reliable method (Table 1 ). The negative predictive value of the $\mathrm{SN}$ method in vulval cancer appeared to be $100 \%$ in most studies, with the identification rate nearly $100 \%$ in those studies using the combined method. Skip metastases, i.e. true negative $\mathrm{SN}$ (using serial sectioning + IHC) with positive nodes at a higher level in the lymphatic chain, are found rarely; only a few case reports have been published on false negative $\mathrm{SNs}^{[40,52,53]}$.

\section{Indication for SND in vulval cancer}

The aim of SN detection is purely diagnostic; only patients with clinically negative groin nodes can be considered for SND. Apparently enlarged/metastatic lymph nodes should be completely debulked in a therapeutic manner. The primary tumour should not invade the anus, urethra or vagina and peritumoural injection of dye/tracer should be feasible. Some authors defined a tumour diameter of equal to or less than $4 \mathrm{~cm}$ as a critical limit for SND ${ }^{[54]}$.

\section{Technique}

The combined use of radiolabelled tracer and blue dye seems to be the most efficient method in the identification of SN in vulval cancer. Lymphoscintigraphy and handheld gamma probe have a high detection rate, which is augmented by the dye; the blue dye in turn can eliminate the 'shine through' effect of the primary lesion and can visualise SNs close to the primary tumour. Tc-99m-labelled colloid $(15 \mathrm{mBq})$ and $2 \mathrm{ml}$ blue dye should be injected subcutaneously into the junction of the tumour and the normal skin, at four sites around the lesion. A total of $60 \mathrm{mBq}$ Tc-99m-labelled colloid and $8 \mathrm{ml}$ blue dye is injected around the tumour. Preoperative administration of Tc-99m $2 \mathrm{~h}$ before the operation is feasible for vulval cancer, however, early administration (1 day prior to surgery) and lymphoscintintigraphy can help to roughly localise the SNs. With a handheld gamma probe the $\mathrm{SN}(\mathrm{s})$ can be localised, then a minor incision is sufficient to remove the $\mathrm{SN}(\mathrm{s})$. The $\mathrm{SN}$ must be sent for frozen section analysis; if the frozen section proves positive for metastatic involvement a complete inguinofemoral lymph node dissection (LND) has to be performed. Theoretically, SNs found negative by frozen section have to undergo serial sectioning and IHC, and in the case of a positive result, a second step LND must be carried out. However, until the results of prospective multicentre studies such as the GOG173 and the European trial on the clinical implementation of SN, a complete inguinofemoral LND must be carried out after SND. If there is no SN detected by the combined method, complete inguinofemoral LND must be performed.

\section{Cervical cancer}

Cervical cancer is a leading cause of cancer death worldwide; however, the introduction of a well-organised screening program based on cervical exfoliative cytology has diminished its incidence in industrialised countries. According to Cancer Research UK, 3000 patients are still diagnosed with cervical cancer each year, and 1100 patients die of it every year in the United Kingdom. Although surgical treatment has become less radical during the past decades, the current gold standard for the management of patients with stage IA2-IB1 cervical cancer (tumours with a maximum diameter of $4 \mathrm{~cm}$ ) is still radical hysterectomy with full diagnostic pelvic LND. Knowledge of the pelvic lymph node status is crucial in decision-making about the treatment, as radical hysterectomy has to be abandoned if metastasis is found in the pelvic nodes. The rate of pelvic lymph node metastasis (LNM) for FIGO stage IA2 cancer is 7\%, and for IB1 cancer it does not exceed $20 \%$, implying that the vast majority of patients will not benefit from pelvic LND ${ }^{[22]}$. However, LND is associated with significant complications, e.g. lymphocyst formation, leg oedema, nerve damage, neurogen bladder, which develop more frequently if postoperative radiotherapy is administered ${ }^{[55-57]}$. Cervical cancer patients with negative pelvic nodes benefit from radical hysterectomy, while those with histologically proven LNM require primary chemoradiation.

In view of the morbidity of pelvic LND, attempts have been made to establish the SN concept in cervical cancer. Since the first study published by Echt et al. in 1999, the SN technique has been improved significantly and high detection rates as well as low false negative $\mathrm{SN}$ rates have been achieved proving the feasibility of the SN concept in cervical cancer (see Table 2). 


\section{Indication and technique}

Only patients with clinical stage IA2 and IB1 are candidates for SND. The principles of the method are similar to that of SND in vulval cancer, i.e. the combined detection technique with serial sectioning and IHC can provide the highest identification rate and negative predictive value.

Injection of radioactive tracer subepithelially around the tumour must be performed on the day prior to surgery. Pelvic and abdominal scintigraphy to roughly localise the site(s) of SN(s) has to be done on the same day. The blue dye must be injected into the same sites of the cervix during anaesthetic induction just prior to the operation; a lower amount of blue dye $(<4 \mathrm{ml})$ has been proved to be inferior ${ }^{[13,16,30]}$. Laparoscopic removal of the SNs guarantees the lowest morbidity ${ }^{[13]}$. Until results from prospective randomised trials are available, complete pelvic LND in addition to a radical hysterectomy must be performed in the case of negative $\mathrm{SN}(\mathrm{s})$.

The $\mathrm{SN}$ is located in the obturator region in $43 \%$ of cases and in the external iliac region in $45 \%-84 \%$ of cases ${ }^{[13,18,30]}$. Skip metastasis, i.e. paraaortic lymph node involvement without pelvic SN metastasis is rare and accounts for only $1 \%$ of cases ${ }^{[28,30,59]}$. Parametrial lymph nodes are often involved by tumour cells and represent a difficulty in detection by a handheld gamma probe due to the 'shine through' effect of the primary tumour. However, these nodes are removed if a radical hysterectomy is performed or irradiated in the case of primary chemoradiation.

The data published during the past 6 years provide evidence that SND in cervical cancer is a feasible and highly accurate method to estimate nodal status. The detection rate with the combined method is $80 \%-$ $100 \%$, the false negative rate is as low as $3 \%-11 \%$ and the negative predictive value is $90 \%-100 \%$ (see Table 2). The application of SND is potentially a useful method to select a subgroup of high risk patients for primary chemoradiation (i.e. positive SNs), by avoiding the morbidity of both radical hysterectomy and complete pelvic LND.

\section{Endometrial cancer}

The incidence of endometrial cancer has shown an increasing trend in industrialised countries. In the UK, 6000 new patients with endometrial cancer are diagnosed every year, with a yearly mortality rate of 1500 (Cancer Research UK). Most of the patients (75\%) present with early stage disease confined to the uterus. Among patients with LNM, 50\% have pelvic LNM only, 30\% have both pelvic and paraaortic LNM, and 20\% have paraaortic LNM alone. The current standard of surgical treatment is total abdominal hysterectomy and bilateral salpingooophorectomy (TAH\&BSO) with or without LND. The selection of patients who benefit from LND and the extent of LND, however, still remain controversial. Complete pelvic and paraaortic LND is associated with significant morbidity, e.g. lymphocyst, lymphoedema, ileus, vascular and urologic injuries; however, less than half of the high risk patients will not have any LNM found by conventional histopathology.

There is little evidence on the feasibility of SND in endometrial cancer. The complex lymphatic drainage as well as the difficulty in injecting radioactive tracer preoperatively questions the feasibility and validity of the SN method in endometrial cancer. In the few publications available, the method of delivery of the tracer was either injection into the cervix, subserosally into the corpus, or into the endometrium during preoperative hysteroscopy. Blue dye methods has proved to be highly unreliable with variable detection rates between $0 \%$ and $100 \%{ }^{[15,17,60-64]}$. Conclusions are difficult to draw as there was only one study where all patients underwent both pelvic and paraaortic LND. There was no consensus on the detection method for $\mathrm{SN}(\mathrm{s})$ as well as on the histopathological method to identify micrometastases. In a series of 28 endometrial cancer patients who underwent office hysteroscopy, subendometrial injection of Tc-99m was performed followed by dynamic scintigraphy. TAH\&BSO with pelvic and paraaortic SND + LND using a handheld gamma probe were performed on each patient ${ }^{[62]}$. A detection rate of $82 \%$ and sensitivity of $100 \%$ was achieved. Interestingly, SNs were identified by scintigraphy within $10 \mathrm{~min}$ after the injection indicating that the injection of the tracer can be performed on the same day as the operation ${ }^{[62]}$.

The high incidence of endometrial cancer, the difficulty of identifying a high risk group preoperatively, and the significant morbidity of pelvic and paraaortic LND indicate that further studies must be conducted on the feasibility and clinical value of the $\mathrm{SN}$ concept in endometrial cancer.

\section{Conclusion}

With the widespread use of less radical oncosurgical practice, SND has found its clinical role in the management of breast cancer and malignant cutaneous melanoma providing reliable information on the lymph node status with significantly decreased morbidity. Similar trends in gynaecological oncology have been observed in the past decade; according to several small series, the combined use of blue dye and lymphoscintigraphy for SND seems to be a reliable technique for vulval cancer. The role of the SN method for cervical cancer is being delineated but is still equivocal for endometrial cancer. Before the standard application of the SN technique as a diagnostic tool, the results of large multicentre trials must be critically evaluated; it must be proved that SND has no negative impact on survival but reduces morbidity. The SN technique must be standardised, as well as the histopathological evaluation of the $\mathrm{SN}(\mathrm{s})$. 
The clinical significance of micrometastases detected by highly sensitive techniques, i.e. IHC or PCR, must also be clarified in the future.

\section{References}

[1] Gould EA, Winship T, Philbin PH, Kerr HH. Observations on a 'sentinel node' in cancer of the parotid. Cancer 1960; 13: 77-8.

[2] Cabanas RM. An approach for the treatment of penile carcinoma. Cancer 1977; 39: 456-66.

[3] Weiser EB, Bundy BN, Hoskins WJ et al. Extraperitoneal versus transperitoneal selective paraaortic lymphadenectomy in the pretreatment surgical staging of advanced cervical carcinoma (a Gynecologic Oncology Group study). Gynecol Oncol 1989; 33: 283-9.

[4] Grigsby PW. Postoperative irradiation in cervical cancer: prognostic factors and outcome. Radiat Med 2004; 22: 106-10.

[5] Denschlag D, Gabriel B, Mueller-Lantzsch C et al. Evaluation of patients after extraperitoneal lymph node dissection for cervical cancer. Gynecol Oncol 2005; 96: 658-64.

[6] Van Trappen PO, Pepper MS. Lymphatic dissemination of tumour cells and the formation of micrometastases. Lancet Oncol 2002; 3: 44-52.

[7] Morton DL, Wen DR, Wong JH et al. Technical details of intraoperative lymphatic mapping for early stage melanoma. Arch Surg 1992; 127: 392-9.

[8] Alex JC, Krag DN. Gamma-probe guided localization of lymph nodes. Surg Oncol 1993; 2: 137-43.

[9] Krag DN, Weaver DL, Alex JC, Fairbank JT. Surgical resection and radiolocalization of the sentinel lymph node in breast cancer using a gamma probe. Surg Oncol 1993; 2: 335-9 (discussion 340).

[10] Giuliano AE, Kirgan DM, Guenther JM, Morton DL. Lymphatic mapping and sentinel lymphadenectomy for breast cancer. Ann Surg 1994; 220: 391-8 (discussion 398-401).

[11] Levenback C, Burke TW, Gershenson DM, Morris M, Malpica A, Ross MI. Intraoperative lymphatic mapping for vulvar cancer. Obstet Gynecol 1994; 84: 163-7.

[12] Echt ML, Finan MA, Hoffman MS, Kline RC, Roberts WS, Fiorica JV. Detection of sentinel lymph nodes with lymphazurin in cervical, uterine, and vulvar malignancies. South Med J 1999; 92: 204-8.

[13] Dargent D, Martin X, Mathevet P. Laparoscopic assessment of the sentinel lymph node in early stage cervical cancer. Gynecol Oncol 2000; 79: 411-5.

[14] Dargent D, Enria R. Laparoscopic assessment of the sentinel lymph nodes in early cervical cancer. Technique-preliminary results and future developments. Crit Rev Oncol Hematol 2003; 48: 305-10.

[15] Barranger E, Cortez A, Grahek D, Callard P, Uzan S, Darai E. Laparoscopic sentinel node procedure using a combination of patent blue and radiocolloid in women with endometrial cancer. Ann Surg Oncol 2004; 11: 344-9.

[16] Barranger E, Grahek D, Cortez A, Talbot JN, Uzan S, Darai E. Laparoscopic sentinel lymph node procedure using a combination of patent blue and radioisotope in women with cervical carcinoma. Cancer 2003; 97: 3003-9.

[17] Lelievre L, Camatte S, Le Frere-belda MA et al. Sentinel lymph node biopsy in cervix and corpus uteri cancers. Int J Gynecol Cancer 2004; 14: 271-8.

[18] Rob L, Strnad P, Robova H et al. Study of lymphatic mapping and sentinel node identification in early stage cervical cancer. Gynecol Oncol 2005; 98: 281-8.

[19] Veronesi U, Paganelli G, Viale G et al. A randomized comparison of sentinel-node biopsy with routine axillary dissection in breast cancer. N Engl J Med 2003; 349: 546-53.

[20] Veronesi U, Galimberti V, Mariani L et al. Sentinel node biopsy in breast cancer: early results in 953 patients with negative sentinel node biopsy and no axillary dissection. Eur J Cancer 2005; 41: 231-7.
[21] Schwartz GF. Clinical practice guidelines for the use of axillary sentinel lymph node biopsy in carcinoma of the breast: current update. Breast J 2004; 10: 85-8.

[22] DiSaia PJ, Creasman TC. Clinical Gynecologic Oncology, 5th edn. Mosby: 1997.

[23] Borgno G, Micheletti L, Barbero M et al. Topographic distribution of groin lymph nodes. A study of 50 female cadavers. J Reprod Med 1990; 35: 1127-9.

[24] DiSaia PJ. What is the proper extent of an inguinal lymphadenectomy for early vulvar cancer? Gynecol Oncol 2003; 90: 687-8.

[25] Hudson CN, Shulver H, Lowe DC. The surgery of 'inguinofemoral' lymph nodes: is it adequate or excessive? Int J Gynecol Cancer 2004; 14: 841-5.

[26] Curry SL, Wharton JT, Rutledge F. Positive lymph nodes in vulvar squamous carcinoma. Gynecol Oncol 1980; 9: 63-7.

[27] Henriksen E. The lymphatic spread of carcinoma of the cervix and of the body of the uterus; a study of 420 necropsies. Am J Obstet Gynecol 1949; 58: 924-42.

[28] Sakuragi N, Satoh C, Takeda N et al. Incidence and distribution pattern of pelvic and paraaortic lymph node metastasis in patients with Stages IB, IIA, and IIB cervical carcinoma treated with radical hysterectomy. Cancer 1999; 85: 1547-54.

[29] Barranger E, Darai E. Lymphatic mapping for gynecologic malignancies. Semin Oncol 2004; 31: 394-402.

[30] Levenback C, Coleman RL, Burke TW et al. Lymphatic mapping and sentinel node identification in patients with cervix cancer undergoing radical hysterectomy and pelvic lymphadenectomy. J Clin Oncol 2002; 20: 688-93.

[31] Burke TW, Levenback C, Tornos C, Morris M, Wharton JT, Gershenson DM. Intraabdominal lymphatic mapping to direct selective pelvic and paraaortic lymphadenectomy in women with high-risk endometrial cancer: results of a pilot study. Gynecol Oncol 1996; 62: 169-73.

[32] Plante M, Renaud MC, Tetu B, Harel F, Roy M. Laparoscopic sentinel node mapping in early-stage cervical cancer. Gynecol Oncol 2003; 91: 494-503.

[33] Fanfani F, Ludovisi M, Zannoni GF et al. Frozen section examination of pelvic lymph nodes in endometrial and cervical cancer: accuracy in patients submitted to neoadjuvant treatments. Gynecol Oncol 2004; 94: 779-84.

[34] Scholz HS, Lax SF, Benedicic C, Tamussino K, Winter R. Accuracy of frozen section examination of pelvic lymph nodes in patients with FIGO stage IB1 to IIB cervical cancer. Gynecol Oncol 2003; 90: 605-9.

[35] Grabau DA, Rank F, Friis E. Intraoperative frozen section examination of axillary sentinel lymph nodes in breast cancer. APMIS 2005; 113: 7-12.

[36] Wada N, Imoto S, Hasebe T, Ochiai A, Ebihara S, Moriyama N. Evaluation of intraoperative frozen section diagnosis of sentinel lymph nodes in breast cancer. Jpn J Clin Oncol 2004; 34: 113-7.

[37] Puig-Tintore LM, Ordi J, Vidal-Sicart S et al. Further data on the usefulness of sentinel lymph node identification and ultrastaging in vulvar squamous cell carcinoma. Gynecol Oncol 2003; 88: 29-34.

[38] Terada KY, Shimizu DM, Wong JH. Sentinel node dissection and ultrastaging in squamous cell cancer of the vulva. Gynecol Oncol 2000; 76: 40-4.

[39] Moore RG, Granai CO, Gajewski W, Gordinier M, Steinhoff MM. Pathologic evaluation of inguinal sentinel lymph nodes in vulvar cancer patients: a comparison of immunohistochemical staining versus ultrastaging with hematoxylin and eosin staining. Gynecol Oncol 2003; 91: 378-82.

[40] Hakam A, Nasir A, Raghuwanshi R et al. Value of multilevel sectioning for improved detection of micrometastases in sentinel lymph nodes in invasive squamous cell carcinoma of the vulva. Anticancer Res 2004; 24(2C): 1281-6.

[41] Gusterson BA. The new TNM classification and micrometastases. Breast 2003; 12: 387-90.

[42] Yabushita H, Shimazu M, Yamada $\mathrm{H}$ et al. Occult lymph node metastases detected by cytokeratin immunohistochemistry predict recurrence in node-negative endometrial cancer. Gynecol Oncol 2001; 80: 139-44. 
[43] Gillanders WE, Mikhitarian K, Hebert R et al. Molecular detection of micrometastatic breast cancer in histopathology-negative axillary lymph nodes correlates with traditional predictors of prognosis: an interim analysis of a prospective multi-institutional cohort study. Ann Surg 2004; 239: 828-37 (discussion 837-40).

[44] Roberts AA, Cochran AJ. Pathologic analysis of sentinel lymph nodes in melanoma patients: current and future trends. J Surg Oncol 2004; 85: 152-61.

[45] Podratz KC, Symmonds RE, Taylor WF, Williams TJ. Carcinoma of the vulva: analysis of treatment and survival. Obstet Gynecol 1983; 61: 63-74.

[46] Hacker NF, Berek JS, Lagasse LD, Leuchter RS, Moore JG. Management of regional lymph nodes and their prognostic influence in vulvar cancer. Obstet Gynecol 1983; 61: 408-12.

[47] Barton DP, Shepherd JH, Moskovic EC, Sohaib SA. Identification of inguinal lymph node metastases from vulval carcinoma by magnetic resonance imaging: an initial report. Clin Radiol 2003; 58: 409 (author reply 409).

[48] Rockall AG, Sohaib SA, Harisinghani MG et al. Diagnostic performance of nanoparticle-enhanced magnetic resonance imaging in the diagnosis of lymph node metastases in patients with endometrial and cervical cancer. J Clin Oncol 2005; 23: 2813-21.

[49] DiSaia PJ, Creasman WT, Rich WM. An alternate approach to early cancer of the vulva. Am J Obstet Gynecol 1979; 133: $825-32$.

[50] Stehman FB, Bundy BN, Dvoretsky PM, Creasman WT. Early stage I carcinoma of the vulva treated with ipsilateral superficial inguinal lymphadenectomy and modified radical hemivulvectomy: a prospective study of the Gynecologic Oncology Group. Obstet Gynecol 1992; 79: 490-7.

[51] Stehman FB, Bundy BN, Ball H, Clarke-Pearson DL. Sites of failure and times to failure in carcinoma of the vulva treated conservatively: a Gynecologic Oncology Group study. Am J Obstet Gynecol 1996; 174: 1128-32 (discussion 1132-3).

[52] Raspagliesi F, Ditto A, Fontanelli R et al. False-negative sentinel node in patients with vulvar cancer: a case study. Int J Gynecol Cancer 2003; 13: 361-3.

[53] Boran N, Kayikcioglu F, Kir M. Sentinel lymph node procedure in early vulvar cancer. Gynecol Oncol 2003; 90: 492-3.

[54] Torne A, Puig-Tintore LM. The use of sentinel lymph nodes in gynaecological malignancies. Curr Opin Obstet Gynecol 2004; 16: $57-64$

[55] Lecuru F, Taurelle R. Transperitoneal laparoscopic pelvic lymphadenectomy for gynecologic malignancies (II). Indications. Surg Endosc 1998; 12: 97-100.

[56] Corn BW, Lanciano RM, Greven KM et al. Impact of improved irradiation technique, age, and lymph node sampling on the severe complication rate of surgically staged endometrial cancer patients: a multivariate analysis. J Clin Oncol 1994; 12: 510-5.

[57] Magrina JF. Complications of irradiation and radical surgery for gynecologic malignancies. Obstet Gynecol Surv 1993; 48: $571-5$.

[58] Decesare SL, Fiorica JV, Roberts WS et al. A pilot study utilizing intraoperative lymphoscintigraphy for identification of the sentinel lymph nodes in vulvar cancer. Gynecol Oncol 1997; 66: 425-8.

[59] Michel G, Morice P, Castaigne D, Leblanc M, Rey A, Duvillard P. Lymphatic spread in stage Ib and II cervical carcinoma: anatomy and surgical implications. Obstet Gynecol 1998; 91: 360-3.

[60] Burke TW, Levenback C, Tornos C, Morris M, Wharton JT, Gershenson DM. Intraabdominal lymphatic mapping to direct selective pelvic and paraaortic lymphadenectomy in women with high-risk endometrial cancer: results of a pilot study. Gynecol Oncol 1996; 62: 169-73.

[61] Pelosi E, Arena V, Baudino B et al. Pre-operative lymphatic mapping and intra-operative sentinel lymph node detection in early stage endometrial cancer. Nucl Med Commun 2003; 24: 971-5.

[62] Niikura H, Okamura C, Utsunomiya H et al. Sentinel lymph node detection in patients with endometrial cancer. Gynecol Oncol
2004; 92: 669-74

[63] Raspagliesi F, Ditto A, Kusamura S et al. Hysteroscopic injection of tracers in sentinel node detection of endometrial cancer: a feasibility study. Am J Obstet Gynecol 2004; 191: 435-9.

[64] Holub Z, Jabor A, Lukac J, Kliment L. Laparoscopic detection of sentinel lymph nodes using blue dye in women with cervical and endometrial cancer. Med Sci Monit 2004; 10: CR587-91 (Epub 2004 Sep 23)

[65] Levenback C, Burke TW, Morris M, Malpica A, Lucas KR, Gershenson DM. Potential applications of intraoperative lymphatic mapping in vulvar cancer. Gynecol Oncol 1995; 59: 216-20.

[66] Rodier JF, Janser JC, Routiot T et al. Sentinel node biopsy in vulvar malignancies: a preliminary feasibility study. Oncol Rep 1999; 6: 1249-52.

[67] Ansink AC, Sie-Go DM, van der Velden J et al. Identification of sentinel lymph nodes in vulvar carcinoma patients with the aid of a patent blue V injection: a multicenter study. Cancer 1999; 86: $652-6$.

[68] de Hullu JA, Hollema H, Piers DA et al. Sentinel lymph node procedure is highly accurate in squamous cell carcinoma of the vulva. J Clin Oncol 2000; 18: 2811-6.

[69] Sideri M, De Cicco C, Maggioni A et al. Detection of sentinel nodes by lymphoscintigraphy and gamma probe guided surgery in vulvar neoplasia. Tumori 2000; 86: 359-63.

[70] De Cicco C, Sideri M, Bartolomei M et al. Sentinel node biopsy in early vulvar cancer. Br J Cancer 2000; 82: 295-9.

[71] Levenback C, Coleman RL, Burke TW, Bodurka-Bevers D, Wolf JK, Gershenson DM. Intraoperative lymphatic mapping and sentinel node identification with blue dye in patients with vulvar cancer. Gynecol Oncol 2001; 83: 276-81.

[72] Molpus KL, Kelley MC, Johnson JE, Martin WH, Jones HW 3rd. Sentinel lymph node detection and microstaging in vulvar carcinoma. J Reprod Med 2001; 46: 863-9.

[73] Tavares MG, Sapienza MT, Galeb NA Jr et al. The use of 99mTcphytate for sentinel node mapping in melanoma, breast cancer and vulvar cancer: a study of 100 cases. Eur J Nucl Med 2001; 28: $1597-604$.

[74] Sliutz G, Reinthaller A, Lantzsch T et al. Lymphatic mapping of sentinel nodes in early vulvar cancer. Gynecol Oncol 2002; 84: $449-52$.

[75] Moore RG, DePasquale SE, Steinhoff MM et al. Sentinel node identification and the ability to detect metastatic tumor to inguinal lymph nodes in squamous cell cancer of the vulva. Gynecol Oncol 2003; 89: 475-9.

[76] Merisio C, Berretta R, Gualdi M et al. Radioguided sentinel lymph node detection in vulvar cancer. Int $\mathbf{J}$ Gynecol Cancer 2005; 15 : 493-7.

[77] Louis-Sylvestre C, Evangelista E, Leonard F, Itti E, Meignan M, Paniel BJ. Sentinel node localization should be interpreted with caution in midline vulvar cancer. Gynecol Oncol 2005; 97: $151-4$.

[78] Verheijen RH, Pijpers R, van Diest PJ, Burger CW, Buist MR, Kenemans P. Sentinel node detection in cervical cancer. Obstet Gynecol 2000; 96: 135-8.

[79] O'Boyle JD, Coleman RL, Bernstein SG, Lifshitz S, Muller CY, Miller DS. Intraoperative lymphatic mapping in cervix cancer patients undergoing radical hysterectomy: a pilot study. Gynecol Oncol 2000; 79: 238-43.

[80] Kamprath S, Possover M, Schneider A. Laparoscopic sentinel lymph node detection in patients with cervical cancer. Am J Obstet Gynecol 2000; 182: 1648.

[81] Malur S, Krause N, Kohler C, Schneider A. Sentinel lymph node detection in patients with cervical cancer. Gynecol Oncol 2001; 80: 254-7.

[82] Lantzsch T, Wolters M, Grimm J et al. Sentinel node procedure in Ib cervical cancer: a preliminary series. Br J Cancer 2001; 85: $791-4$.

[83] Rhim CC, Park JS, Bae SN, Namkoong SE. Sentinel node biopsy as an indicator for pelvic nodes dissection in early stage cervical cancer. J Korean Med Sci 2002; 17: 507-11.

[84] Lambaudie E, Collinet P, Narducci F et al. Laparoscopic 
identification of sentinel lymph nodes in early stage cervical cancer: prospective study using a combination of patent blue dye injection and technetium radiocolloid injection. Gynecol Oncol 2003; 89: 84-7.

[85] Chung YA, Kim SH, Sohn HS, Chung SK, Rhim CC, Namkoong SE. Usefulness of lymphoscintigraphy and intraoperative gamma probe detection in the identification of sentinel nodes in cervical cancer. Eur J Nucl Med Mol Imaging 2003; 30: 1014-7.

[86] Buist MR, Pijpers RJ, van Lingen A et al. Laparoscopic detection of sentinel lymph nodes followed by lymph node dissection in patients with early stage cervical cancer. Gynecol Oncol 2003; 90: 290-6.

[87] Hubalewska A, Sowa-Staszczak A, Huszno B et al. Use of Tc-99m-nanocolloid for sentinel nodes identification in cervical cancer. Nucl Med Rev Cent East Eur 2003; 6: 127-30.

[88] van Dam PA, Hauspy J, Vanderheyden T et al. Intraoperative sentinel node identification with Technetium-99m-labeled nanocolloid in patients with cancer of the uterine cervix: a feasibility study. Int J Gynecol Cancer 2003; 13: 182-6.

[89] Martinez-Palones JM, Gil-Moreno A, Perez-Benavente MA, Roca I, Xercavins J. Intraoperative sentinel node identification in early stage cervical cancer using a combination of radiolabeled albumin injection and isosulfan blue dye injection. Gynecol Oncol 2004; 92: 845-50.

[90] Li B, Zhang WH, Liu L, Wu LY, Zhang R, Li N. Sentinel lymph node identification in patients with early stage cervical cancer undergoing radical hysterectomy and pelvic lymphadenectomy. Chin Med J (Engl) 2004; 117: 867-70.

[91] Marchiole P, Buenerd A, Scoazec JY, Dargent D, Mathevet P.
Sentinel lymph node biopsy is not accurate in predicting lymph node status for patients with cervical carcinoma. Cancer 2004; 100: 2154-9.

[92] Barranger E, Cortez A, Commo F et al. Histopathological validation of the sentinel node concept in cervical cancer. Ann Oncol 2004; 15: 870-4.

[93] Niikura H, Okamura C, Akahira J, Takano T, Ito K, Okamura K, Yaegashi N. Sentinel lymph node detection in early cervical cancer with combination $99 \mathrm{mTc}$ phytate and patent blue. Gynecol Oncol 2004; 94: 528-32.

[94] Pijpers R, Buist MR, van Lingen A et al. The sentinel node in cervical cancer: scintigraphy and laparoscopic gamma probeguided biopsy. Eur J Nucl Med Mol Imaging 2004; 31: 1479-86.

[95] Di Stefano AB, Acquaviva G, Garozzo G et al. Lymph node mapping and sentinel node detection in patients with cervical carcinoma: A 2-year experience. Gynecol Oncol 2005; 99: 671-9.

[96] Silva LB, Silva-Filho AL, Traiman P et al. Sentinel node detection in cervical cancer with $(99 \mathrm{~m}) \mathrm{Tc}$-phytate. Gynecol Oncol 2005; 97: 588-95.

[97] Angioli R, Palaia I, Cipriani C et al. Role of sentinel lymph node biopsy procedure in cervical cancer: a critical point of view. Gynecol Oncol 2005; 96: 504-9.

[98] Gil-Moreno A, Diaz-Feijoo B, Roca I et al. Total laparoscopic radical hysterectomy with intraoperative sentinel node identification in patients with early invasive cervical cancer. Gynecol Oncol 2005; 96: 187-93.

[99] Lin YS, Tzeng CC, Huang KF, Kang CY, Chia CC, Hsieh JF. Sentinel node detection with radiocolloid lymphatic mapping in early invasive cervical cancer. Int J Gynecol Cancer 2005; 15: 273-7. 